\title{
SARS-CoV-2-Associated Cerebrovascular Disease Amid the COVID-19 Pandemic: A Systematic Review
}

\author{
Tao Yu ${ }^{1} *$ \\ Hongquan Wang ${ }^{2, *}$ \\ Shuhan Zheng' \\ Liang Huo' \\ 'Department of Pediatrics, Shengjing \\ Hospital of China Medical University, \\ Shenyang, I 1 0004, Liaoning, People's \\ Republic of China; ${ }^{2}$ Tianjin Medical \\ University Cancer Institute and Hospital, \\ National Clinical Research Center for \\ Cancer, Key Laboratory of Cancer \\ Prevention and Therapy, Tianjin's Clinical \\ Research Center for Cancer, Tianjin, \\ 300060, People's Republic of China
}

*These authors contributed equally to this work
Correspondence: Liang Huo Department of Pediatrics, Shengjing Hospital of China Medical University, No. 36 Sanhao Street, Shenyang, Liaoning, I 10004, People's Republic of China Email huol@sj-hospital.org
Background: Cerebrovascular diseases associated with SARS-CoV-2 are being increasingly reported in the literature as the coronavirus disease 2019 (COVID-19) pandemic continues. However, a case-based retrospective analysis of the literature about SARS-CoV-2-cerebrovascular disease (SCVD) is not yet well established. Thus, we reviewed the literature on SCVD covering a comprehensive range of topics spanning the clinical features, mechanism, treatment, and outcomes of patients with SCVD.

Methods: We searched PubMed ${ }^{\circledR}$ and included single-case reports and case series with full text in English that reported original data of patients with CVD and a confirmed recent SARS-CoV-2 infection. Clinical data were extracted.

Results: We included all 51 articles indexed in PubMed $^{\circledR}$ that were published between January 1, 2020, and June 20, 2020. The selected studies reported a total of 167 cerebrovascular events including ischemic stroke, cerebral hemorrhage, subarachnoid hemorrhage, and cerebral venous thrombosis in patients with confirmed COVID-19. The detailed demographic and clinical characteristics of patients with CVD are summarized.

Conclusion: This summary of patient characteristics may help clinicians better anticipate SCVD outcomes and complications in their COVID-19 patients.

Keywords: COVID-19, cerebrovascular disease, stroke, cerebral hemorrhage, cerebral venous thrombosis

\section{Introduction}

The severe acute respiratory syndrome coronavirus 2 (SARS-CoV-2), which causes coronavirus disease 2019 (COVID-19), first resulted in a severe outbreak of pneumonia in December 2019. ${ }^{1}$ COVID-19 then rapidly spread worldwide and was declared a pandemic by the WHO in March 2020 and became a global health threat. COVID-19 has since presented unprecedented challenges to the healthcare systems in almost every country in the world. ${ }^{2}$

The major predominant clinical manifestations of COVID-19 are due to pulmonary complications including fever, cough, hemoptysis, and dyspnea, among others. Xiang et al from Beijing Ditan Hospital reported for the first time a case of viral encephalitis caused by SARS-CoV-2 attacking the central nervous system (CNS) on March 4, 2020. ${ }^{3}$ They confirmed the presence of SARS-CoV-2 in the cerebrospinal fluid by genome sequencing, indicating that COVID-19 has the potential to cause nervous system damage. A retrospective consecutive case series of 214 patients with moderate-to-severe COVID-19 reported, for the first time, an 
early view of the incidence and types of neurologic complications, ranging from fairly specific symptoms (eg, stroke) to more nonspecific symptoms (eg, headache, loss of consciousness, dizziness, or seizure) ${ }^{4}$ Since this case and retrospective consecutive case series ${ }^{4}$ first described the involvement of CNS, further research on COVID-19associated neurologic complications has emerged in the form of case reports and case series. ${ }^{1,5-10}$

Our group has reported the clinical features of COVID19-associated meningitis-encephalitis, ${ }^{11}$ Guillain-Barré syndrome, ${ }^{12}$ and acute disseminated encephalomyelitis (ADEM). ${ }^{13}$ Other reported neurologic manifestations mainly include anosmia, ${ }^{14}$ Miller-Fisher syndrome, and polyneuritis cranialis, ${ }^{15}$ neuromuscular disorders, ${ }^{16}$ facial nerve palsy, ${ }^{17}$ acute necrotizing hemorrhagic encephalopathy, ${ }^{18}$ and acute necrotizing myelitis. ${ }^{19}$ In sum, COVID-19-associated neurologic complications can further be subdivided into three major categories, ${ }^{2,20}$ namely the neurological consequences of the associated pulmonary and systemic disease including stroke, direct CNS invasion by the virus including encephalitis, and post-infectious and potentially immune-mediated complications.

SARS-CoV-2 is known to invade human cells after binding to the angiotensin converting enzyme 2 (ACE2) receptor. Latest research has shown that internalization of the coronavirus requires not only binding to ACE2 but also priming of the viral spike protein by the transmembrane protease serine 2 (TMPRSS2). ${ }^{21,22}$ Such a cleavage step is necessary for the actual virus-host cell membrane fusion and subsequent cell entry. ${ }^{23}$ Thus, ACE2-expressing cells like cerebrovascular endothelial cells may also be the target cells for SARS-CoV -2 infection. Among these, acute cerebrovascular disease (CVD), with a multifactorial etiology, remains one of the most common and serious neurologic complications associated with COVID-19. ${ }^{18}$

Evidence of the existence and importance of stroke in persons infected with COVID-19 has emerged in case studies and case reports, ${ }^{24,25}$ but these have not been synthesized into a comprehensive review. Moreover, a growing body of cases or case series on SCVD is also now available, but the data have not been systematically reviewed. The present study therefore aimed to perform a comprehensive review and identify clinical cases with COVID-19 complicated by CVD - including ischemic stroke, cerebral hemorrhage, subarachnoid hemorrhage, and cerebral venous thrombosis - to establish possible demographic, clinical, laboratory patterns, and prognostic features of these cases. With this review, we hope to clearly define cerebrovascular events related to SCVD to better understand the clinical, epidemiological, laboratory, and radiological characteristics of SCVD, as well as its course, severity, and treatment options.

\section{Methods}

\section{Patient and Public Involvement}

Patients and the public were not directly involved in the design and/or implementation of this study.

\section{Data Collection}

MEDLINE (accessed from PubMed) was systematically searched from January 1, 2020 and June 20, 2020 for related published articles. The following search strategy was implemented and these key words were used: "COVID-19" OR "SARS-CoV-2" (in the title/abstract) AND "stroke" OR "ischemic stroke" OR "cerebrovascular disease" OR "cerebral hemorrhage" OR "subarachnoid hemorrhage" OR "cerebral venous thrombosis" (in the title/abstract or text). ${ }^{6}$ The present study included COVID-19-associated case reports, case series, retrospective studies, prospective studies, scoping review, systematic reviews and meta-analyses, clinical guidelines, and narrative reviews focusing on CVD. Additional articles were included through a manual review of references in listed articles to find relevant articles. ${ }^{8}$ Studies were not restricted according to design, but only studies published in English were considered. At least two independent reviewers independently screened all publications including the title and abstract to determine whether the studies included cases. Then, one reviewer independently retrieved the clinical variables from the selected articles. Preprinted articles were not included. The final list of eligible articles was generated based on relevance to CVD and included 51 papers.

\section{Results}

\section{COVID-19 and Acute Ischemic Stroke (AIS)}

We identified and included 31 articles published between January 1, 2020 and June 20, 2020 in the databases researched. These studies reported a total of 119 AIS cases with confirmed COVID-19 (COVID-19-AIS) and consisted of 15 single-case reports and 16 case series (Table 1 and Supplemental Table 1). The mean age of the 119 patients (51 male [42.9\%] and 30 female [25.2\%]; the sex of the remaining 38 patients was unknown) with COVID-19-AIS was $61.8 \pm 14.1$ years. 
Table I Clinical Characteristics of the 119 COVID-19 Patients with Acute Ischemic Stroke

\begin{tabular}{|c|c|}
\hline \multicolumn{2}{|l|}{ Ischemic Stroke Patients ( $n=119)$} \\
\hline Characteristic & Value $(n=44)$ \\
\hline Median age (years, range) & $62-64$ \\
\hline Male sex, $n(\%)$ & $5 I(42.9)$ \\
\hline Female sex, $n(\%)$ & $30(25.2)$ \\
\hline $\begin{array}{l}\text { Duration, median (range, days) } \\
\text { Time interval from COVID-19 to stroke (days) }\end{array}$ & $9.0(0-33)$ \\
\hline $\begin{array}{l}\text { General symptoms before the onset of the AIS, } \mathrm{n}(\%) \\
\text { Cough } \\
\text { Fever } \\
\text { Hypoxia } \\
\text { Dyspnea } \\
\text { Myalgia and fatigue } \\
\text { Headache } \\
\text { Gastrointestinal manifestations }\end{array}$ & $\begin{array}{l}85(71.4) \\
65(54.4) \\
60(50.4) \\
30(25.2) \\
20(16.8) \\
9(7.6) \\
3(2.5) \\
7(5.9)\end{array}$ \\
\hline $\begin{array}{l}\text { Risk factor, } \mathrm{n}(\%) \\
\text { Hypertension } \\
\text { Diabetes } \\
\text { Hyperlipidemia } \\
\text { Coronary artery disease } \\
\text { Atrial fibrillation } \\
\text { Prior stroke } \\
\text { Previous valvular diseases } \\
\text { Previous cancers }\end{array}$ & $\begin{array}{l}85(71.4) \\
59(49.6) \\
32(26.9) \\
28(23.5) \\
12(10.1) \\
13(10.9) \\
6(5.0) \\
2(1.7) \\
4(3.4)\end{array}$ \\
\hline $\begin{array}{l}\text { Signs and symptoms of stroke, } \mathrm{n}(\%) \\
\text { Hemiplegia/hemiparesis } \\
\text { Reduced consciousness } \\
\text { Weakness of limbs } \\
\text { Dysarthria } \\
\text { Facial droop } \\
\text { Aphasia } \\
\text { Ataxia } \\
\text { Dysphasia }\end{array}$ & $\begin{array}{l}61(51.3) \\
19(16.0) \\
19(16.0) \\
14(14.3) \\
12(10.1) \\
10(8.4) \\
7(5.9) \\
7(5.9) \\
3(2.5)\end{array}$ \\
\hline $\begin{array}{l}\text { Stroke mechanism, } \mathrm{n}(\%) \\
\text { Large artery atherosclerosis } \\
\text { Small vessel disease } \\
\text { Cryptogenic } \\
\text { Cardioembolic stroke }\end{array}$ & $\begin{array}{l}59(47.1) \\
9(7.5) \\
21(17.6) \\
21(17.6)\end{array}$ \\
\hline $\begin{array}{l}\text { Laboratory values, } \mathrm{n}(\%) \\
\text { Increased D-dimer } \\
\text { Normal D-dimer } \\
\text { Increased CRP } \\
\text { Normal CRP }\end{array}$ & $\begin{array}{l}80(67.2) \\
12(10.0) \\
50(42.0) \\
33(27.7)\end{array}$ \\
\hline $\begin{array}{l}\text { Treatment, } \mathrm{n}(\%) \\
\text { Anticoagulation } \\
\text { Intravenous thrombolysis } \\
\text { Mechanical thrombectomy }\end{array}$ & $\begin{array}{l}46(38.7) \\
15(12.6) \\
18(15.1)\end{array}$ \\
\hline
\end{tabular}

(Continued)
Table I (Continued).

\begin{tabular}{|c|c|}
\hline \multicolumn{2}{|l|}{ Ischemic Stroke Patients ( $n=1$ 19) } \\
\hline Characteristic & Value $(n=44)$ \\
\hline Clot retrieval & $\mathrm{II}(9.2)$ \\
\hline Aspirin & $18(15.1)$ \\
\hline Clopidogrel & $\mathrm{II}(9.2)$ \\
\hline Aspirin and clopidogrel & $9(7.6)$ \\
\hline \multicolumn{2}{|l|}{ Outcomes, $n(\%)$} \\
\hline Fatal outcome & $32(26.9)$ \\
\hline Poor (ie, bedridden, hospitalized, critically ill, ICU stay) & $2 \mathrm{I}(17.6)$ \\
\hline
\end{tabular}

COVID-19-AIS was more common in male than female patients, with a male:female sex ratio of 1.7:1. Cough $(n=65,54.6 \%)$; fever $(n=60,50.4 \%)$; and hypoxia $(n=30$, $25.2 \%$ ) were the most prevalent clinical manifestations in the 119 patients with COVID-19-AIS. Other reported symptoms included dyspnea $(n=20,16.8 \%)$; myalgia and fatigue $(n=9,7.6 \%)$; headache $(n=3,2.5 \%)$; and gastrointestinal manifestations $(\mathrm{n}=7,5.9 \%)$. Table 1 presents the details of demographics and clinical characteristics of the 119 patients.

Out of the 119 patients, $85(71.4 \%)$ presented with comorbidities. The most frequent complications for stroke were hypertension $(\mathrm{n}=59,49.6 \%)$; diabetes $(\mathrm{n}=32,26.9 \%)$; hyperlipidemia $(\mathrm{n}=28,23.5 \%)$; coronary artery disease $(\mathrm{n}=12,10.1 \%)$; atrial fibrillation $(\mathrm{n}=13,10.9 \%)$; prior stroke $(\mathrm{n}=6,5.0 \%)$; previous valvular diseases $(\mathrm{n}=2$, $1.7 \%)$, and previous cancers $(n=4,3.4 \%)$. Sixty-one patients $(51.3 \%)$ had signs and symptoms of stroke. Of these 61 patients, 24 were younger than 50 years. The most common reported symptoms were hemiplegia/hemiparesis $(n=19,16.0 \%)$; reduced consciousness $(n=19$, $16.0 \%)$; weakness of limbs ( $\mathrm{n}=14,14.3 \%)$; dysarthria $(\mathrm{n}=12,10.1 \%)$; and facial droop $(\mathrm{n}=10,8.4 \%)$. The other signs and symptoms of stroke include aphasia $(\mathrm{n}=7,5.9 \%)$; ataxia $(\mathrm{n}=7,5.9 \%)$; and dysphasia $(\mathrm{n}=3,2.5 \%)$.

Of the 119 patients, only $74(62.2 \%)$ patients had a record of the time interval from first COVID-19 symptoms to ischemic stroke symptom onset, with a median time interval of 9 days (range: $0-33$ ). Thirty-three patients had data on the National Institutes of Health Stroke Scale (NIHSS) (scores range from 0 to 42, with higher numbers indicating greater stroke severity) score upon stroke onset. The median NIHSS score was calculated as 16.0 (range: 1-36). Of the patients with AIS, 56 were large vessel stenosis and 9 had small vessel occlusion; and 17.6\% 
(21/119) were of cryptogenic subtype and $17.6 \%(21 / 119)$ met the criteria for cardioembolic stroke. Moreover, $67.2 \%$ (80/119) patients had high D-dimer levels closest to the time of the stroke; $10 \%(12 / 119)$ patients had normal D-dimer levels. Fifty patients (50/119, 42.0\%) had high CRP and 33 (33/119, 27.7\%) had normal CRP levels.

Forty-six patients received anticoagulation, 15 patients received intravenous thrombolysis, 18 patients had mechanical thrombectomy, and 11 patients underwent clot retrieval. Antiplatelet therapy was started with aspirin and clopidogrel in 18 and 11 patients, respectively. Nine patients received dual antiplatelet therapy with aspirin and clopidogrel. Further, 17.6\% (21/119) did poorly, ie, were bedridden, hospitalized, critically ill, or remained in the intensive care unit (ICU). Overall, 26.9\% (32/119) patients had a fatal outcome.

\section{COVID-19 and Cerebral Hemorrhage}

We selected 17 studies that reported a total of 33 acute cerebral hemorrhage cases with confirmed COVID-19 (COVID-19-CH) (Table 2 and Supplemental Table 2). Out of the 33 patients with COVID-19-CH, 72.7\% (24/33) were male (mean age: $58.8 \pm 14.2$ years and $27.3 \%(9 / 33)$ were female (mean age: $56.0 \pm 14.1$ years). The male:female sex ratio was $2.7: 1$.

Of these 33 patients, parenchymal hemorrhages involved the frontal lobe in 11 patients, parietal lobe in 5 patients, temporal lobe in 5 patients, brain stem in 4 patients, basal ganglia in 4 patients, and cerebellar hemisphere in 2 patients. Three patients had acute hemorrhage after intra-cerebral biopsy in COVID-19 patients. Twentynine patients $(29 / 33,87.9 \%)$ had signs and symptoms of cerebral hemorrhage. Of the 33 patients, seven $(7 / 33$, $21.82 \%$ ) were younger than 50 years. The most common reported hemorrhage symptoms were reduced consciousness $(n=8,24.2 \%)$ and altered pupils $(n=9,27.2 \%)$. All patients demonstrated areas of hemorrhage on brain computed tomography $(\mathrm{CT})(\mathrm{n}=28)$ or MRI $(\mathrm{n}=7)$ upon onset of nervous system symptoms. In total, $60.6 \%$ (20/33) of patients did poorly or died.

\section{COVID-19 and Subarachnoid}

\section{Hemorrhage}

Three studies reported on a total of three subarachnoid hemorrhage cases complicated by COVID-19 (COVID19-SAH) (Supplemental Table 3). The mean age was 52.6 years (two men and one woman). All patients had
Table 2 Clinical Characteristics of the 33 COVID-19 Patients with Cerebral Hemorrhage

\begin{tabular}{|c|c|}
\hline \multicolumn{2}{|l|}{ Cerebral Hemorrhage Patients $(n=33)$} \\
\hline Characteristic & $\begin{array}{l}\text { Value } \\
(N=33)\end{array}$ \\
\hline Median age (range, years) & $58(|9-8|)$ \\
\hline Male sex, $n(\%)$ & $24(72.7)$ \\
\hline Female sex, $n(\%)$ & $9(27.3)$ \\
\hline \multicolumn{2}{|l|}{$\begin{array}{l}\text { General symptoms before the onset of cerebral } \\
\text { hemorrhage, } n(\%)\end{array}$} \\
\hline Cough & $15(45.5)$ \\
\hline Fever & $15(45.5)$ \\
\hline Shortness of breath/Dyspnea & 13(39.4) \\
\hline Gastrointestinal manifestations & $7(5.9)$ \\
\hline \multicolumn{2}{|l|}{ Risk factor, $n(\%)$} \\
\hline Hypertension & $10(30.3)$ \\
\hline Diabetes & $6(18.2)$ \\
\hline Hyperlipidemia & $2(6.1)$ \\
\hline None & $7(21.2)$ \\
\hline Atrial fibrillation & $\mathrm{I}(3.0)$ \\
\hline Aortic valve replacement & $\mathrm{I}(3.0)$ \\
\hline Previous cancers & $2(6.1)$ \\
\hline Signs and symptoms of stroke, $n(\%)$ & 29(87.9) \\
\hline Reduced consciousness & $8(24.2)$ \\
\hline Altered pupils & $9(27.2)$ \\
\hline GCS, n(\%) & $7(21.2)$ \\
\hline GCS, mean (range) & $8.7(3-13)$ \\
\hline \multicolumn{2}{|l|}{ Location of cerebral hemorrhage, $n(\%)$} \\
\hline Frontal lobe & II(33.3) \\
\hline Parietal lobe & $5(15.2)$ \\
\hline Temporal lobe & $5(15.2))$ \\
\hline Brain stem & $4(12.1)$ \\
\hline Basal ganglia & $4(\mid 2.1)$ \\
\hline Cerebellar hemisphere & $2(6.1)$ \\
\hline \multicolumn{2}{|l|}{ Laboratory values, n(\%) } \\
\hline Increased D-dimer & $16(48.5)$ \\
\hline Increased CRP & $8(24.0)$ \\
\hline Normal CRP & $4(12.1)$ \\
\hline \multicolumn{2}{|l|}{ Treatment, n \%) } \\
\hline Anticoagulation & $7(21.2)$ \\
\hline \multicolumn{2}{|l|}{ Outcomes, n(\%) } \\
\hline Dead & $16(48.5)$ \\
\hline Poor & $4(12.1)$ \\
\hline Discharged & $7(21.2)$ \\
\hline
\end{tabular}

signs and symptoms of SAH. The reported hemorrhage symptoms were loss of consciousness in two patients, seizures in one patient, and headache in one patient. 


\section{COVID-19 and Cerebral Venous}

\section{Thrombosis}

Seven studies reported 12 patients with COVID-19 presenting with cerebral venous system thrombosis (CVT) (Table 3 and Supplemental Table 4). The mean age was 52.6 \pm 15.8 years (range, 23-81 years; eight men and four women). Five patients younger than 44 years with confirmed SARS-Cov-2 infection had neurologic findings related to cerebral venous thrombosis. The median time from COVID-19 symptoms to a thrombotic event was 11.4 days (range, 2-20 days).

Out of the 12 patients, 7 (58\%) cases presented with comorbidities, the most frequent complications being hypertension $(\mathrm{n}=3,25 \%)$; diabetes $(\mathrm{n}=2,16.7 \%)$; previous stroke $(\mathrm{n}=1,8.3 \%)$; and previous cancers $(\mathrm{n}=2,16.7 \%)$. One patient used oral contraceptive pills. The thrombosis involved the transverse sinus $(n=6)$, sigmoid sinus $(n=4)$, straight sinus $(\mathrm{n}=5)$, vein of Galen $(\mathrm{n}=4)$, internal cerebral veins $(n=4)$, sagittal sinus $(n=4)$, torcular herophili $(n=3)$, internal jugular vein $(n=1)$, straight vein $(n=1)$, and the deep medullary veins $(\mathrm{n}=1)$. Computed tomography showed hemorrhagic venous infarction in six patients. Overall, $41.7 \%(5 / 12)$ patients had a fatal outcome.

\section{Discussion}

Growing evidence shows that neurological complications associated with COVID-19, especially CVD, are on the rise per literature in the form of case reports and case series. ${ }^{26-32}$ However, a case-based comprehensive analysis of the literature about SCVD is still missing. Thus, this systematic review was conducted to better define the cerebrovascular events related to SCVD, eventually leading to a better understanding of SCVD clinical characteristics with the goal of contributing to existing knowledge of COVID-19. Thus, we conducted an analysis of the available data based on cases or case series on SCVD, and performed a comprehensive review by identifying clinical cases with COVID-19 complicated by CVD such as AIS, $\mathrm{CH}, \mathrm{SAH}$, and CVT to establish possible demographic, clinical, laboratory patterns, and prognostic features of these cases. To our knowledge, this is the first case-based comprehensive retrospective analysis of clinical cases with COVID19 complicated by CVD.

Research during the early stages of the pandemic was mainly centered on the respiratory manifestations, as they were the most salient and emergent aspects of the disease;
Table 3 Clinical Characteristics of the 119 COVID-19 Patients with Cerebral Venous Thrombosis

\begin{tabular}{|c|c|}
\hline \multicolumn{2}{|l|}{ Cerebral Venous Thrombosis Patients $(n=12)$} \\
\hline Characteristic & Value $(\mathrm{N}=44)$ \\
\hline Median age (range, years) & $52.6(23-81)$ \\
\hline Male sex, $\mathrm{n}(\%)$ & $8(66.7)$ \\
\hline Female sex, $n(\%)$ & $4(33.3)$ \\
\hline Duration, median (range, days) & \\
\hline Time interval from COVID-19 to stroke (days) & II.4 (2-24) \\
\hline General symptoms before the onset of the AIS, $n(\%)$ & \\
\hline Cough & $5(4 I .7)$ \\
\hline Fever & $8(66.7)$ \\
\hline Myalgia and fatigue & $9(7.6)$ \\
\hline Headache & $I(8.3)$ \\
\hline Gastrointestinal manifestations & $\mathrm{I}(8.3)$ \\
\hline Risk factor, $n(\%)$ & $7(58.0)$ \\
\hline Hypertension & $3(25.0)$ \\
\hline Diabetes & $2(16.7)$ \\
\hline Hyperlipidemia & $28(23.5)$ \\
\hline On oral contraceptive pills & $\mathrm{I}(8.3)$ \\
\hline Previous stroke & $\mathrm{I}(8.3)$ \\
\hline Previous cancers & $2(16.7)$ \\
\hline Signs and symptoms of stroke, $n(\%)$ & \\
\hline Reduced consciousness & $7(58.3)$ \\
\hline Headache & $4(33.3)$ \\
\hline Laboratory values, $\mathrm{n}(\%)$ & \\
\hline Increased D-dimer & $8(66.7)$ \\
\hline Normal D-dimer & $\mathrm{I}(8.3)$ \\
\hline Increased CRP & $4(33.3)$ \\
\hline Normal CRP & $\mathrm{I}(8.3)$ \\
\hline Increased normal fibrinogen & $\mathrm{I}(8.3)$ \\
\hline Normal fibrinogen & $4(33.3)$ \\
\hline Location of thrombosis, $-n(\%)$ & \\
\hline Transverse sinus & $6(50.0)$ \\
\hline Sigmoid sinus & $4(33.3)$ \\
\hline Straight sinus & $5(4 \mid .7))$ \\
\hline Vein of Galen & $4(33.3)$ \\
\hline Internal cerebral veins & $4(33.3)$ \\
\hline Sagittal sinus & $4(33.3)$ \\
\hline Torcular herophili & $3(25.0)$ \\
\hline Deep medullary veins & $\mathrm{I}(8.3)$ \\
\hline Straight vein & $\mathrm{I}(8.3)$ \\
\hline Internal jugular vein & $\mathrm{I}(8.3)$ \\
\hline Deep medullary veins & $\mathrm{I}(8.3)$ \\
\hline
\end{tabular}

(Continued) 
Table 3 (Continued).

\begin{tabular}{|l|l|}
\hline \multicolumn{2}{|l|}{ Cerebral Venous Thrombosis Patients $(n=12)$} \\
\hline Characteristic & Value (N= 44) \\
\hline Treatment, $n(\%)$ & \\
Anticoagulation & $6(50.0)$ \\
Mechanical thrombec3tomy & $2(16.7)$ \\
\hline Outcomes, $n(\%)$ & \\
Fatal outcome & $5(38.5)$ \\
Discharged & $2(16.7)$ \\
\hline
\end{tabular}

however, different kinds of neurologic complications emerged later. The neurologic manifestations, especially cerebrobasilar disease, started receiving increasing attention. Mounting evidence indicates that SARS-CoV-2 infection causes acute cerebrobasilar disease by causing cytokine storm syndromes. ${ }^{33,34}$ An increasing number of cases with COVID-19-AIS have been reported. The earliest and largest retrospective analysis came from a retrospective case series of 214 hospitalized patients with confirmed COVID-19 by Mao et $\mathrm{al}^{4}$ who showed that $5 \%$ of the hospitalized patients had acute strokes, which comprised AIS in 11 patients, CVT in one, and ICH in one. Another study on 138 admitted COVID-19 patients by Wang et al documented seven patients (5.1\%) with comorbid $\mathrm{CVD}^{35}$ These observations were corroborated by a singlecenter retrospective study of 221 admitted COVID-19 patients in Wuhan, wherein $5.9 \%$ patients (13/221) reportedly developed acute cerebrovascular events: 11 patients $(5 \%)$ developed AIS, one (0.5\%) had CVT, and one $(0.5 \%)$ had ICH. In summary, multiple studies have reported that SARS-CoV-2 may invade the CNS, causing acute cerebrobasilar disease.

In this comprehensive retrospective study based on published cases or case series, we discuss the key demographic and clinical characteristics of patients with COVID-19 who develop CVD including AIS, CH, SAH, and CVT. In all, 51 studies were identified in the databases searched after exclusion based on the title and abstract, and 167 patients with COVID-19 who developed CVD were selected-119 patients with AIS, 33 with $\mathrm{CH}$, three with $\mathrm{SAH}$, and 12 with CVT. The incidence of AIS, $\mathrm{CH}, \mathrm{SAH}$, and CVT was $71.2 \%, 19.8 \%, 1.8 \%$, and $7.2 \%$, respectively.

Patients with COVID-19 complicated by concomitant CVD were significantly older, more likely to present with severe manifestations, have cardiovascular risk factors, and significantly higher C-reactive protein and D-dimer levels suggestive of a hypercoagulable state, ${ }^{1}$ leading to CVD confirmed to be an independent risk factor associated with fatal outcome. ${ }^{36}$ According to the literature review, the mean age of patients with COVID-19 who developed AIS, CH, SAH, and CVT was 56 years, and AIS patients were older than those in the remaining three groups. A recent published systematic review on the neurological findings of patients with COVID-19 found that more than one-third of these CVD patients eventually died. ${ }^{6}$ According to the results of the present review, 34\% patients $(57 / 167)$ had a fatal outcome, which is partially corroborated by the aforementioned study.

In this study, we found that many patients with SCVD also had hypertension and diabetes. Some studies have reported that patients with diabetes and hypertension belong to high-risk groups with respect to COVID-19. In particular, type 2 diabetes and hyperglycemia are strong negative factors determining the prognosis of COVID-19. ${ }^{37,38}$ Sardu Celestino et al reported that IL-6 and D-dimer levels remained high in patients with hyperglycemia during hospitalization, despite all patients receiving standard treatment for COVID-19 infection. ${ }^{39,40}$ Because the increased IL-6 and D-dimer levels are important risk factors for cerebrovascular disease, COVID-19 patients with hyperglycemia and diabetes are at a significantly increased risk of serious CVD. Other studies have shown that the prognosis of patients with hypertension combined COVID-19 is poor, especially hypertensive patients on ACE inhibitors and/or angiotensin receptor blocker therapy have a higher likelihood of serious complications. ${ }^{41}$ This is because SARS-CoV-2 can cause disease through ACE2, which is found on the endothelium of human blood vessels. Therefore, when SARS-CoV-2 enters the human body through ACE2, it will not only cause hypertension but also cause CVD. For COVID-19 patients with hypertension, the risk of CVD is higher than in those without hypertension.

The rare cause of stroke - CVT-that makes up for approximately $0.5 \%$ of all stroke cases and results in $4 \%$ mortality is reported in patients with COVID-19. Accumulating evidence has recognized that COVID-19 can result in a prothrombotic state, ${ }^{32,42-44}$ leading to the development of CVT. ${ }^{45}$ CVT can present with a broad variety of neurologic signs and symptoms. Chougar et al reported an atypical deep CVT complicated with hemorrhagic venous infarction in a patient positive for SARS-CoV-2 with no risk factors for thrombosis. Therefore, the diagnosis of COVID19-associated CVT can be challenging. Recognition of neurological manifestations such as headache with or without other focal neurological symptoms should be emphasized, as the number of patients diagnosed with CVT continues to increase 
worldwide. A recent study has shown that the degree of D-dimer elevation is associated with the severity of and the incidence of CVT. ${ }^{46}$ In this retrospective analysis, the D-dimer levels were $>2000 \mu \mathrm{g} / \mathrm{L}$ in all patients at diagnosis, even reaching $55,000 \mu \mathrm{g} / \mathrm{L}$ in one case. Early identification is hence becoming more crucial, because prompt appropriate management can likely improve the final outcomes. Here, we need to be careful not to confuse COVID-19 with SARSCOV2, as COVID-19 is a pathogenic status caused by SARSCoV2. A significant percentage of patients are asymptomatic, and interestingly, these patients show an increased risk of acute thrombosis and worse prognosis. ${ }^{47}$ To date, as in the case of asymptomatic patients, there is a pro-thrombotic status with acute arterial (intra coronary) thrombosis and worse prognosis. $^{47}$

There are several limitations to this case-based comprehensive analysis of the literature evaluating CVD complications connected to COVID-19. This study is a retrospective analysis, and the studies included in this review may have inherent bias. In addition, most of the patients with COVID-19 were admitted to the general internal medicine department or ICU; thus, the studies included may lack neurologic history reported in medical records and detailed reporting of neurologic comorbidities in acutely reported cases, which present further challenges to neurologic assessments in patients with COVID-19. These studies likely contributed to the lack of neurologic history, neurology imaging, and neurological assessment and grades score such as NIHHS or GCS. Further, these conditions have contributed to the lower reported incidence of neurologic comorbidities or events in hospitalized patients.

\section{Conclusion}

Given that the patient presented with signs and symptoms of stroke, physicians should be particularly aware of SCVD. ${ }^{48}$ The diagnostic key for SCVD lies in the detection of an initiating imaging. Familiarity with the characteristic findings and awareness of the possibility of SCVD onset is necessary to avoid misdiagnosis and commence urgent and necessary intervention for SCVD. Cerebrovascular disease is the common neurological complication in patients with COVID-19. However, the cases of SARS-CoV-2-associated CVD that were reported lack direct evidence, and CVD appears to occur more frequently and with more severity in patients with COVID19 than in those without. Hence, early identification is becoming more crucial, because prompt and appropriate management may improve the final outcomes.

\section{Data Sharing Statement}

The data that support the findings of this study are all included in the present study. Data sharing not applicable no new data generated.

\section{Acknowledgments}

The authors would like to thank Prof. Liqiang Zheng at the Department of Medical Statistics, Library in Shengjing Hospital of China Medical University, for help with statistical analysis. We are also very grateful to Prof. Hua Wang for her support with the 345 Talent Project.

\section{Author Contributions}

All authors contributed to data analysis, drafting or revising the article, have agreed on the journal to which the article will be submitted, gave final approval of the version to be published, and agree to be accountable for all aspects of the work.

\section{Funding}

Liang Huo, Liaoning Provincial Department of Education Scientific Research Project (No. QNZR2020012). Liang Huo, CAAE Epilepsy Research Fund (CX-B-2021-02).

\section{Disclosure}

The authors have no conflicts of interest to declare.

\section{References}

1. Zubair AS, McAlpine LS, Gardin T, Farhadian S, Kuruvilla DE, Spudich S. Neuropathogenesis and neurologic manifestations of the coronaviruses in the age of coronavirus disease 2019: a review. JAMA Neurol. 2020;77(8):1018. doi:10.1001/jamaneurol.2020.2065

2. Koralnik IJ, Tyler KL. COVID -19: a global threat to the nervous system. Ann Neurol. 2020;88:1-11. doi:10.1002/ana.25807

3. Wu Y, Xu X, Chen Z, et al. Nervous system involvement after infection with COVID-19 and other coronaviruses. Brain Behav Immun. 2020. doi:10.1016/j.bbi.2020.03.031

4. Mao L, Jin H, Wang M, et al. Neurologic manifestations of hospitalized patients with coronavirus disease 2019 in Wuhan, China. JAMA Neurol. 2020;77(6):683. doi:10.1001/jamaneurol.2020.1127

5. Ahmad I, Rathore FA. Neurological manifestations and complications of COVID-19: a literature review. J Clin Neurosci. 2020;77:8-12. doi:10.1016/j.jocn.2020.05.017

6. Asadi-Pooya AA, Simani L. Central nervous system manifestations of COVID-19: a systematic review. J Neurol Sci. 2020;413:116832. doi:10.1016/j.jns.2020.116832

7. Bridwell R, Long B, Gottlieb M. Neurologic complications of COVID-19. Am J Emerg Med. 2020;38(7):1549.e3-1549.e7. doi:10.1016/j.ajem.2020.05.024

8. Herman C, Mayer K, Sarwal A. Scoping review of prevalence of neurologic comorbidities in patients hospitalized for COVID-19. Neurology. 2020;95(2):77-84. doi:10.1212/WNL.0000000000009673

9. Nath A. Neurologic complications of coronavirus infections Neurology. 2020;94(19):809-810. doi:10.1212/WNL.000000000 0009455 
10. Payus AO, Liew Sat Lin C, Mohd Noh M, Jeffree MS, Ali RA. SARS-CoV-2 infection of the nervous system: a review of the literature on neurological involvement in novel coronavirus disease (COVID-19). Bosn J Basic Med Sci. 2020. doi:10.17305/ bjbms. 2020.4860

11. Huo L, Xu KL, Wang H. Clinical features of SARS-CoV-2-associated encephalitis and meningitis amid COVID-19 pandemic. World J Clin Cases. 2021;9(5):1058-1078. doi:10.12998/wjcc.v9.i5.1058

12. Li X, Wang Y, Wang H, Wang Y. SARS-CoV-2-associated GuillainBarré syndrome is a para-infectious disease. QJM. 2021;114 (9):625-635. doi:10.1093/qjmed/hcab157

13. Wang Y, Wang Y, Huo L, Li Q, Chen J, Wang H. SARS-CoV -2-associated acute disseminated encephalomyelitis: a systematic review of the literature. $J$ Neurol. 2021;1-22. doi:10.1007/s00415021-10771-8

14. Politi LS, Salsano E, Grimaldi M. Magnetic resonance imaging alteration of the brain in a patient with coronavirus disease 2019 (COVID-19) and anosmia. JAMA Neurol. 2020;77(8):1028. doi:10.1001/jamaneurol.2020.2125

15. Gutiérrez-Ortiz C, Méndez A, Rodrigo-Rey S, et al. Miller Fisher syndrome and polyneuritis cranialis in COVID-19. Neurology. 2020;95(5):e601-e605. doi:10.1212/WNL.0000000000009619

16. Guidon AC, Amato AA. COVID-19 and neuromuscular disorders. Neurology. 2020;94(22):959-969. doi:10.1212/WNL.00000000 00009566

17. Goh Y, Beh D, Makmur A, Somani J, Chan A. Pearls and Oy-sters: facial nerve palsy as a neurological manifestation of Covid-19 infection. Neurology. 2020;95:364-367. doi:10.1212/WNL.0000000000009863

18. Poyiadji N, Shahin G, Noujaim D, Stone M, Patel S, Griffith B. COVID-19-associated acute hemorrhagic necrotizing encephalopathy: CT and MRI features. Radiology. 2020;201187. doi:10.1148/ radiol.2020201187

19. Sotoca J, Rodríguez-álvarez Y. COVID-19-associated acute necrotizing myelitis. Neurol Neuroimmunol Neuroinflamm. 2020;7(5):e803. doi:10.1212/NXI.0000000000000803

20. Jasti M, Nalleballe K, Dandu V, Onteddu S. A review of pathophysiology and neuropsychiatric manifestations of COVID-19. J Neurol. 2020;268:2007-2012. doi:10.1007/s00415-020-09950-w

21. D' Onofrio N, Scisciola L, Sardu C, et al. Glycated ACE2 receptor in diabetes: open door for SARS-COV-2 entry in cardiomyocyte. Cardiovasc Diabetol. 2021;20(1):99. doi:10.1186/s12933-02101286-7

22. Sardu C, Gambardella J, Morelli MB, Wang X, Marfella R, Santulli G. Hypertension, thrombosis, kidney failure, and diabetes: is COVID-19 an endothelial disease? A comprehensive evaluation of clinical and basic evidence. J Clin Med. 2020;9(5):1417. doi:10.3390/ jcm9051417

23. Matarese A, Gambardella J, Sardu C, Santulli G. miR-98 regulates TMPRSS2 expression in human endothelial cells: key implications for COVID-19. Biomedicines. 2020;8(11):462. doi:10.3390/ biomedicines 8110462

24. Hernández-Fernández F, Valencia HS, Barbella-Aponte RA, et al. Cerebrovascular disease in patients with COVID-19: neuroimaging, histological and clinical description. Brain. 2020;143(10):3089-3103. doi:10.1093/brain/awaa239

25. Rothstein A, Oldridge O, Schwennesen H, Do D, Cucchiara BL. Acute cerebrovascular events in hospitalized COVID-19 patients. Stroke. 2020;STROKEAHA120030995. doi:10.1161/ STROKEAHA.120.030995

26. Beyrouti R, Adams ME, Benjamin L, et al. Characteristics of ischaemic stroke associated with COVID-19. J Neurol Neurosurg Psychiatry. 2020. doi:10.1136/jnnp-2020-323586

27. Chougar L, Mathon B, Weiss N, Degos V, Shor N. Atypical deep cerebral vein thrombosis with hemorrhagic venous infarction in a patient positive for COVID-19. AJNR Am J Neuroradiol. 2020. doi:10.3174/ajnr.A6642
28. Heman-Ackah SM, Su YS, Spadola M, et al. Neurologically devastating intraparenchymal hemorrhage in COVID-19 patients on extracorporeal membrane oxygenation: a case series. Neurosurgery. 2020;87(2):E147-E151. doi:10.1093/neuros/nyaa198

29. Larson AS, Savastano L, Kadirvel R, Kallmes DF, Hassan AE, Brinjikji W. COVID-19 and the cerebro-cardiovascular systems: what do we know so far. J Am Heart Assoc. 2020;e016793. doi:10.1161/JAHA.120.016793

30. Oxley TJ, Mocco J, Majidi S, et al. Large-vessel stroke as a presenting feature of Covid-19 in the young. $N$ Engl $J$ Med. 2020;382(20):e60. doi:10.1056/NEJMc2009787

31. Vu D, Ruggiero M, Choi WS, et al. Three unsuspected CT diagnoses of COVID-19. Emerg Radiol. 2020;27(3):229-232. doi:10.1007/ s10140-020-01775-4

32. Zhang Y, Xiao M, Zhang S, et al. Coagulopathy and antiphospholipid antibodies in patients with covid-19. N Engl J Med. 2020;382(17): e38. doi:10.1056/NEJMc2007575

33. Fan S, Xiao M, Han F, et al. Neurological manifestations in critically ill patients with COVID-19: a Retrospective Study. Front Neurol. 2020;11:806. doi:10.3389/fneur.2020.00806

34. Mehta P, McAuley DF, Brown M, Sanchez E, Tattersall RS, Manson JJ. COVID-19: consider cytokine storm syndromes and immunosuppression. Lancet. 2020;395(10229):1033-1034. doi:10.1016/S0140-6736(20)30628-0

35. Wang D, Hu B, Hu C, et al. Clinical characteristics of 138 hospitalized patients with 2019 novel coronavirus-infected Pneumonia in Wuhan, China. JAMA. 2020. doi:10.1001/jama.2020.1585

36. Chen R, Liang W, Jiang M, et al. Risk factors of fatal outcome in hospitalized subjects with coronavirus disease 2019 from a nationwide analysis in China. Chest. 2020. doi:10.1016/j. chest.2020.04.010

37. Sardu C, D’Onofrio N, Balestrieri ML, et al. Outcomes in patients with hyperglycemia affected by COVID-19: can we do more on glycemic control. Diabetes Care. 2020;43(7):1408-1415. doi: $10.2337 / \mathrm{dc} 20-0723$

38. Sardu C, Gargiulo G, Esposito G, Paolisso G, Marfella R. Impact of diabetes mellitus on clinical outcomes in patients affected by Covid-19. Cardiovasc Diabetol. 2020;19(1):76. doi:10.1186/s12933020-01047-y

39. Sardu C, D'Onofrio N, Balestrieri ML, et al. Hyperglycaemia on admission to hospital and COVID-19. Diabetologia. 2020;63 (11):2486-2487. doi:10.1007/s00125-020-05216-2

40. Marfella R, Paolisso P, Sardu C, et al. Negative impact of hyperglycaemia on tocilizumab therapy in Covid-19 patients. Diabetes Metab. 2020;46(5):403-405. doi:10.1016/j.diabet.2020.05.005

41. Sardu C, Maggi P, Messina V, et al. Could anti-hypertensive drug therapy affect the clinical prognosis of hypertensive patients with COVID-19 infection? data from centers of Southern Italy. $\mathrm{J} \mathrm{Am}$ Heart Assoc. 2020;9(17):e016948. doi:10.1161/JAHA.120.016948

42. Han H, Yang L, Liu R, et al. Prominent changes in blood coagulation of patients with SARS-CoV-2 infection. Clin Chem Lab Med. 2020;58(7):1116-1120. doi:10.1515/cclm-2020-0188

43. Helms J, Tacquard C, Severac F, et al. High risk of thrombosis in patients with severe SARS-CoV-2 infection: a multicenter prospective cohort study. Intensive Care Med. 2020;46(6):1089-1098. doi:10.1007/s00134-020-06062-x

44. Klok FA, Kruip M, van der Meer N, et al. Incidence of thrombotic complications in critically ill ICU patients with COVID-19. Thromb Res. 2020;191:145-147. doi:10.1016/j.thromres.2020.04.013

45. Garaci F, Di Giuliano F, Picchi E, Da Ros V, Floris R. Venous cerebral thrombosis in COVID-19 patient. $J$ Neurol Sci. 2020;414:116871. doi:10.1016/j.jns.2020.116871

46. Yang J, Zheng Y, Gou X, et al. Prevalence of comorbidities and its effects in patients infected with SARS-CoV-2: a systematic review and meta-analysis. Int J Infect Dis. 2020;94:91-95. doi:10.1016/j. ijid.2020.03.017 
47. Marfella R, Paolisso P, Sardu C, et al. SARS-COV-2 colonizes coronary thrombus and impairs heart microcirculation bed in asymptomatic SARS-CoV-2 positive subjects with acute myocardial infarction. Crit Care. 2021;25(1):217. doi:10.1186/s13054-021-03643-0
48. Pinzon RT, Wijaya VO, Buana RB, Al Jody A, Nunsio PN Neurologic characteristics in coronavirus disease 2019 (COVID-19): a systematic review and meta-analysis. Front Neurol. 2020;11:565. doi:10.3389/fneur.2020.00565

\section{Publish your work in this journal}

Infection and Drug Resistance is an international, peer-reviewed openaccess journal that focuses on the optimal treatment of infection (bacterial, fungal and viral) and the development and institution of preventive strategies to minimize the development and spread of resistance. The journal is specifically concerned with the epidemiology of

Submit your manuscript here: https://www.dovepress.com/infection-and-drug-resistance-journa| antibiotic resistance and the mechanisms of resistance development and diffusion in both hospitals and the community. The manuscript management system is completely online and includes a very quick and fair peerreview system, which is all easy to use. Visit http://www.dovepress.com/ testimonials.php to read real quotes from published authors. 